\title{
A review of free-piston engine history and applications.
}

\author{
R. Mikalsen, A.P. Roskilly* \\ Sir Joseph Swan Institute for Energy Research, Newcastle University, Newcastle upon Tyne, NE1 7RU, United Kingdom.
}

\begin{abstract}
This document reviews the history of free-piston internal combustion engines, from the air compressors and gas generators used in the mid-20th century through to recent free-piston hydraulic engines and linear electric generators. Unique features of the free-piston engine are presented and their effects on engine operation are discussed, along with potential advantages and disadvantages compared to conventional engines. The paper focuses mainly on developed engines where operational data has been reported. Finally, the potential of the free-piston engine is evaluated and the most promising designs identified.
\end{abstract}

Key words: free-piston, linear engine.

\section{Introduction}

Extensive use of fossil fuels as an energy source for both sea and land based transport leads to significant amounts of $\mathrm{CO}_{2}$ and other pollutants being produced. Much research, particularly within the automotive industry, is being undertaken to develop more environmental friendly fuel chains, and the fuel cell vehicle stands out as a promising technology for the future. Although superior in vehicle efficiency, the implementation barriers for such radical technology change are huge, and the complete fuel chain ('well-to-wheel') efficiencies are not yet superior to those of conventional technology [1]. Hybrid electric vehicles powered by conventional internal combustion engines have the potential to realise large emission reductions within a significantly shorter timescale.

After being abandoned in the mid-20th century, free-piston engines are being investigated by a number of research groups worldwide as an alternative

\footnotetext{
* Corresponding author.

Email address: Tony.Roskilly@ncl.ac.uk (A.P. Roskilly).
}

to conventional engine-generator sets or for generating hydraulic power in off-highway vehicles. Potential advantages of the free-piston engine include optimised combustion through variable compression ratio, leading to higher part load efficiency and possible multi-fuel operation, and reduced frictional losses due to a simple design with few moving parts.

This document reviews the history of the freepiston engine with emphasis on recent applications, and investigates the potential of free-piston engines as an alternative to conventional technology. It is the result of an extensive background study on the subject and will be followed up by a more detailed design study and the development of a prototype engine.

\section{Free-piston engine basics}

Due to the breadth of the free-piston term, many engine configurations will fall under this category. The free-piston term is most commonly used to distinguish a linear engine from a rotating crankshaft engine. The piston is 'free' because its motion is not restricted by the position of a rotating crankshaft, 
as known from conventional engines, but only determined by the interaction between the gas and load forces acting upon it.

This gives the free-piston engine some distinct characteristics, including (a) variable stroke length and (b) the need for active control of piston motion. Other important features of the free-piston engine are potential reductions in frictional losses and possibilities to optimise engine operation using the variable compression ratio.

\subsection{The original}

R.P. Pescara [2] is usually credited with the invention of the free-piston engine with his patent dating from 1928, but other vendors, among others Junkers in Germany, were also working on free-piston machinery at this time. Since then, a high number of patents describing free-piston machinery or related to such machinery have been published. ${ }^{1}$ The original Pescara patent describes a single piston spark ignited air compressor but the patent seeks to protect a large number of applications utilising the freepiston principle.

Pescara started his work on free-piston engines around 1922 and he developed prototypes with both spark ignition (1925) and diesel combustion (1928). The latter led to the development of the Pescara free-piston air compressor [4]. Pescara continued his work on free-piston machinery and also patented a multi-stage free-piston air compressor engine in 1941 $[5]$.

\subsection{Piston configuration}

Free-piston engines are usually divided into three categories based on the piston/cylinder configuration. A fourth category, free-piston gas generators, identifies engines where the load is extracted purely from an exhaust turbine and not from a load device mechanically coupled to the engine.

Below follows a description of the different categories of free-piston engines.

\subsubsection{Single piston}

A single piston free-piston engine is shown in Figure 1. This engine essentially consists of three parts: a combustion cylinder, a load device, and a rebound

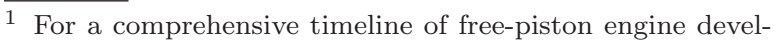
opments, see Aichlmayr [3].
}

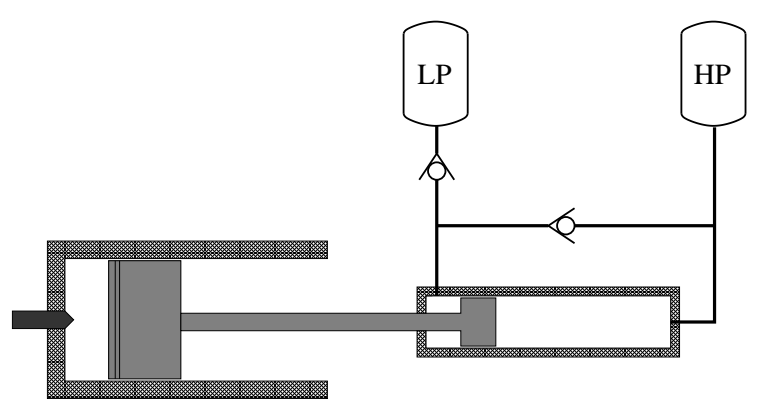

Fig. 1. Single piston hydraulic free-piston engine [6].

device to store the energy required to compress the next cylinder charge. In the engine shown in the figure the hydraulic cylinder serves as both load and rebound device, whereas in other designs these may be two individual devices, for example an electric generator and a gas filled bounce chamber.

A simple design with high controllability is the main strength of the single piston design compared to the other free-piston engine configurations. The rebound device may give the opportunity to accurately control the amount of energy put into the compression process and thereby regulating the compression ratio and stroke length.

\subsubsection{Dual piston}

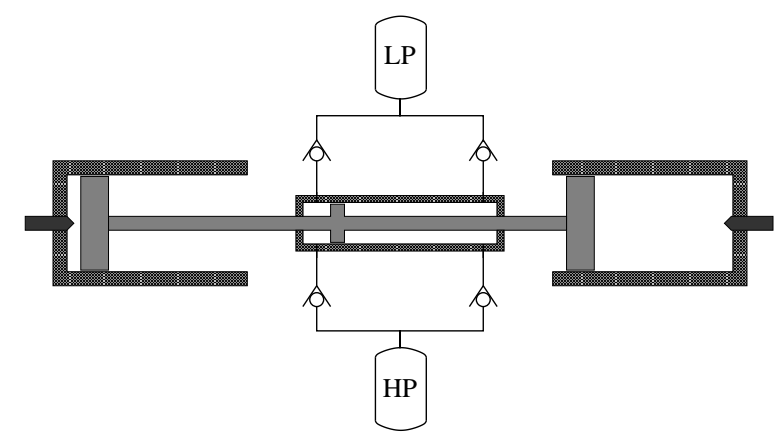

Fig. 2. Hydraulic dual piston free-piston engine [7].

The dual piston (or dual combustion chamber) configuration, shown in Figure 2, has been topic for much of the recent research in free-piston engine technology. A number of dual piston designs have been proposed and a few prototypes have emerged, both with hydraulic and electric power output. The dual piston engine configuration eliminates the need for a rebound device, as the (at any time) working piston provides the work to drive the compression process in the other cylinder. This allows a simple and more compact device with higher power to weight ratio. 
Some problems with the dual piston design have, however, been reported. The control of piston motion, in particular stroke length and compression ratio, has proved difficult. This is due to the fact that the combustion process in one cylinder drives the compression in the other, and small variations in the combustion will have high influence on the next compression. This is a control challenge if the combustion process is to be controlled accurately in order to optimise emissions and/or efficiency $[3,8]$. Experimental work with dual piston engines has reported high sensitivity to load nuances and high cycle-tocycle variations $[9,10]$.

\subsubsection{Opposed piston}

An opposed piston free-piston engine essentially consists of two single piston units with a common combustion chamber. Each piston requires a rebound device, and a load device may be coupled to one or both of the pistons. Figure 3 shows an opposed piston free-piston engine, with a mechanical piston synchronisation mechanism.

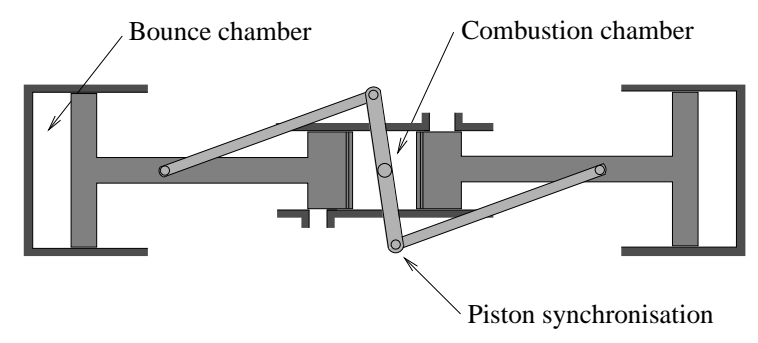

Fig. 3. Illustration of an opposed piston free-piston engine with piston synchronisation mechanism.

The opposed piston principle was used almost exclusively in the early free-piston engine designs (1930-1960), and mechanical linkages connected the two pistons to ensure symmetric piston motion, as illustrated in the figure. These engines served successfully as air compressors and later as gas generators in large-scale plants, often with a number of units feeding a single power turbine.

The main advantage of the opposed piston configuration is the perfectly balanced and vibrationfree design. This feature is not shared by any of the other free-piston configurations, which need alternative means of controlling vibrations. A further advantage of the opposed piston design is reduced heat transfer losses due to the opposed piston cylinder (elimination of the cylinder head), and this also allows uniflow scavenging to be used, giving high scavenging efficiency.
The absolute need for a piston synchronisation mechanism is the most important disadvantage of the opposed piston design. This, together with the need for a dual set of the main components, makes the engine complicated and bulky. Achten [8] considers the opposed piston design and rejects this, and the only modern opposed piston free-piston design reported is the hydraulic engine developed by Hibi and Ito [11].

\subsubsection{Gas generators}

Free-piston gas generators (or gasifiers) are freepiston engines feeding hot gas to a power turbine. The only 'load' for the engine itself is that to supercharge the intake air, the output work is taken out entirely from the power turbine. Free-piston gas generators were used in some large-scale marine and stationary powerplants in the mid-20th century, and attempts were made to use this principle in automotive applications. Figure 4 illustrates an opposed piston free-piston gas generator plant.

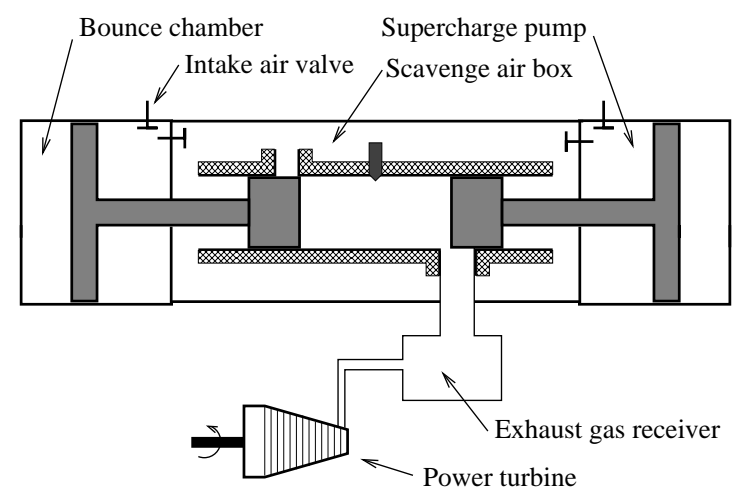

Fig. 4. Illustration of a free-piston gas generator

Compared to a conventional gas turbine, the freepiston gas generator has the advantage of high compression and pressure ratios. It further differs in the way that the work needed to compress the intake air is already extracted from the gas when supplied to the power turbine. Consequently, the gas fed to the turbine holds a lower temperature which reduces the materials requirements and allows the turbine to be placed further away from the combustor without extensive heat transfer losses.

The operational characteristics of a free-piston gas generator do not differ much from those of other free-piston engines of the same configuration. The opposed piston free-piston gas generator was the topic of much research in the mid-20th century and many reports can be found describing the design 
and operation of such engines. However, as conventional gas turbine technology matured, the freepiston gas generator concept was abandoned. The only reported modern application of this concept is the single piston free-piston gas generator presented by Johansen et al. [12].

\section{Free-piston engine unique features}

The free-piston engine has a number of unique features, some give it potential advantages and some represent challenges that must be overcome for the free-piston engine to be a realistic alternative to conventional technology.

\subsection{Operating principle}

The free-piston engine is restricted to the twostroke operating principle, as a power stroke is required on every cycle. Although two-stroke engines suffer from poorer performance compared to fourstrokes, this performance gap is declining and recent years have seen an increased interest in small scale two-stroke engines.

\subsection{Piston dynamics and control}

In conventional engines, the crank mechanism and flywheel serve as both piston motion control and energy storage. The piston motion control ensures sufficient compression in one end and sufficient time for scavenging in the other, while the energy storage provides energy for the compression of the next charge. In the free-piston engine the motion of the mover at any point in the cycle is determined by the sum of the forces acting upon it. Hence, the interaction of these forces must be arranged in a way that ensures the mover motion is within acceptable limits for all types of operation if the concept is to be feasible.

For an engine as shown in Figure 5a, one can derive the mover motion mathematically using a free-body diagram as shown in Figure 5b. The forces working on the mover are: combustion chamber pressure force $F_{C}$, bounce chamber (rebound) force $F_{R}$, load force $F_{L} \cdot x$ denotes mover position, $\mathrm{TDC}_{\mathrm{N}}$ and $\mathrm{BDC}_{\mathrm{N}}$ illustrate nominal top dead centre and bottom dead centre positions and ML are the mechanical limits of the motion. The mover itself will have a mass $m_{\mathrm{p}}$.

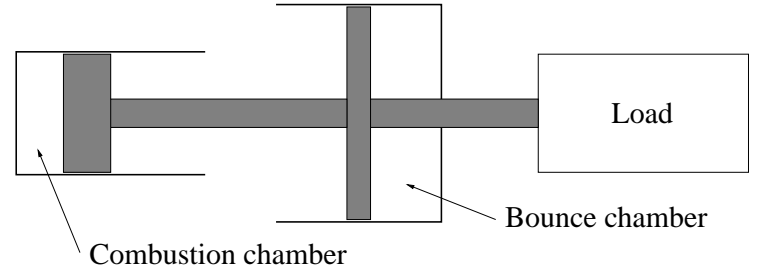

(a) Single piston free-piston engine configuration.

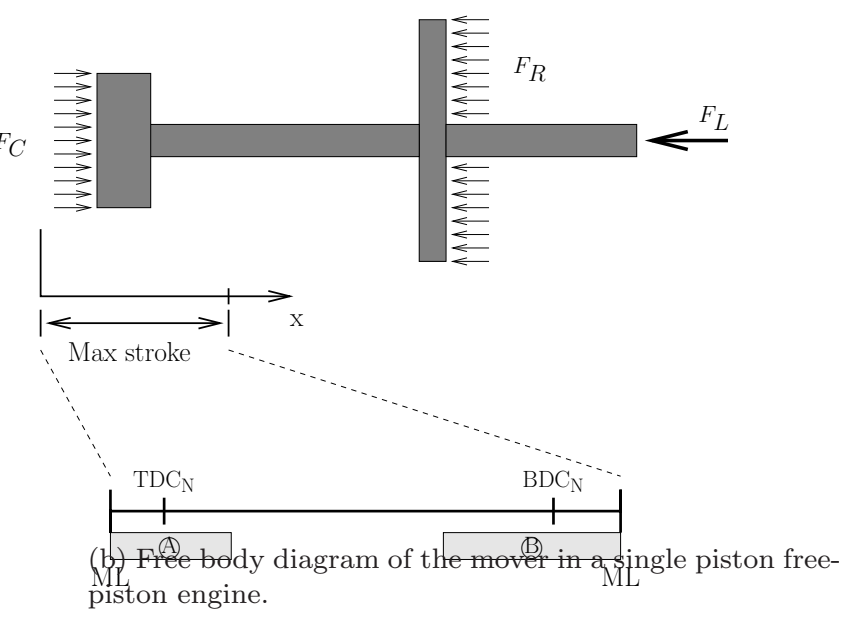

Fig. 5. Piston dynamics of a single piston free-piston engine.

Applying Newtons 2nd law to the moving mass in Figure $5 \mathrm{~b}$, the piston motion can be described with

$\sum_{i} F_{i}=m_{p} \frac{\mathrm{d}^{2} x}{\mathrm{~d} t^{2}}$

Knowing that the combustion cylinder and the bounce chamber will have characteristics similar to those of a gas spring, it becomes clear that they will produce a bouncing-type motion of the piston. Adding a load force, this must have appropriate characteristics or be subordinate the other two to ensure a reciprocating motion of the piston. If a rebound device with other force-position characteristics than a bounce chamber is used, such as a hydraulic cylinder, the operational characteristics will be slightly different but the same principles will apply.

Figure $5 \mathrm{~b}$ further shows the different parts of the engine stroke. Area (A) shows the piston position range where the compression ratio of the engine is sufficient for fuel autoignition. For the engine to run, engine TDC must be within this area. Area (B) shows the piston position range where the scavenging ports are open and the burnt gases can be replaced with fresh charge. For the scavenging to be efficient, the 
piston needs to spend a sufficient amount of time in this area in every cycle.

These requirements are absolute and for the engine to be practical, an engine control system needs to be able to meet these requirements for all types of engine operation. Accurate control of piston motion currently represents one of the biggest challenges for developers of free-piston engines.

\subsubsection{Frequency control}

For an engine with a gas filled bounce chamber, the spring-mass nature of the system means that the frequency and stroke length are closely related. The system will operate at its natural frequency, and the pressure in the gas springs (i.e. spring stiffness) can only be varied over a limited range. The stroke length is strictly limited by the need for sufficient compression and scavenging, hence there will likely be limitations in the frequency control possibilities of the engine. This also limits the power output range of such free-piston engines, which has been noted by a number of authors as a problem with the free-piston design.

For engines with different types of rebound devices, very high levels of controllability can be achieved. The best example of this is the Pulse Pause Modulation (PPM) scheme for hydraulic free-piston engines, presented by Achten et al. [13]. The same principle has been employed by several other authors.

The Pulse Pause Modulation frequency control pauses the piston motion at BDC using a controllable hydraulic cylinder as rebound device. At BDC the piston velocity is zero and the upwards motion will only begin when the rebound device releases the stored energy. The frequency can therefore be controlled by applying a pause between the time the piston reaches BDC and the release of compression energy for the next stroke. The frequency can in theory be varied down towards zero, there is no minimum frequency like the idle speed in conventional engines. This is possible because the piston motion in each stroke is not frequency-dependent - the motion profile will have the same form regardless of operating frequency.

Another consequence of this is that the frequency will not largely influence the efficiency of the engine. A conventional engine may have to operate over a range of inefficient speeds or torques and only parts of the operational time on the design conditions. Both Hibi and Ito [11] and Achten et al. [13] report very good part-load performance for hydraulic freepiston engines using PPM and Achten et al. present a direct comparison to a conventional engine-pump showing significantly better part-load performance for the free-piston engine.

Such frequency control also allows frequency changes to take place instantaneously and step wise. Somhorst and Achten [14] report an idle speed of the Innas Free-Piston Engine with auxiliaries of $1 \mathrm{~Hz}(60 \mathrm{rpm})$. An illustration of the principle is shown in Figure 6.

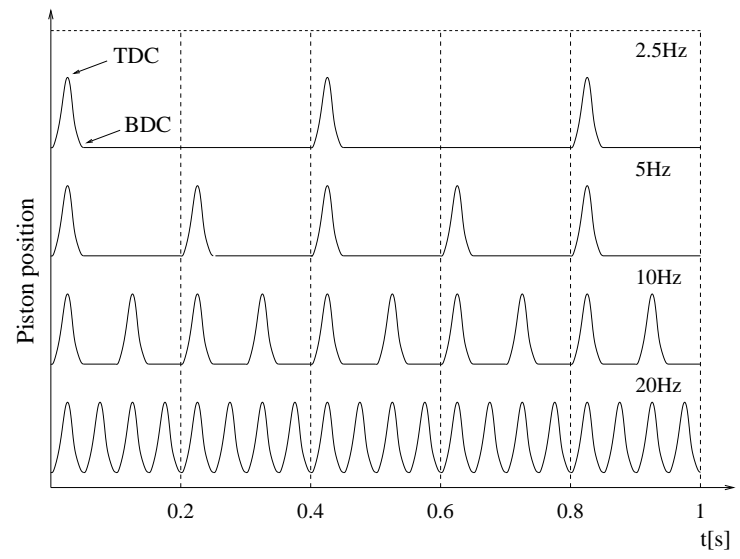

Fig. 6. The principle of pulse pause modulation frequency control of a single-piston free-piston engine with $20 \mathrm{~Hz}$ maximum frequency [14].

\subsubsection{Starting}

The free-piston engine cannot be cranked over several revolutions for starting like conventional engines and other methods for starting must therefore be implemented. Starting can be achieved by impulsing the piston to give it sufficient energy to reach top dead centre, or by driving the piston back and forth until it reaches sufficient compression. The latter can be achieved if the load device can be run as motor, e.g. with an electric machine or a hydraulic cylinder. If the impulse strategy is used, it is crucial that the engine starts on the first stroke and that the engine control system is able to keep the engine running after this.

The mid-1900's engines mainly used compressed air to aid starting, by rapidly introducing it into the bounce chamber. Achieving combustion on the first stroke was not reported to be a problem, because high compression ratios were achievable with this method. More challenging was to immediately control the amount of air in the bounce chamber to achieve sufficient scavenging for stroke number two, 
since the bounce chamber was now full of high pressure starting air. Although some reports indicate that starting was a challenge for the free-piston engines, this is never mentioned as a crucial problem.

Most linear engine generator concepts use the electric machine in motoring mode to start the engine. Recent single piston and opposed piston hydraulic free-piston engines use stored hydraulic energy to start the engine. Since the rebound devices in these engines are hydraulic cylinders, the first stroke is not different from any other stroke and starting represents no problem.

\subsubsection{Misfiring}

Misfiring may represent a problem in the freepiston engine, since it does not have energy storage capable of driving the engine for several revolutions like the flywheel in a conventional engine. Hence, if the engine fails to build up sufficient compression or if other factors influence the injection/ignition and combustion, the engine may stop. The same result may follow from a mistiming in the fuel injection or ignition timing.

Although this has often been mentioned as a potential problem in theoretical surveys on free-piston engine feasibility, such problems are not mentioned by any of the reported experimental work on freepiston engines reviewed.

\subsection{Free-piston loads}

The free-piston engine requires a linear load, and for the overall system to be efficient the load must provide efficient energy conversion. The rotating power source, such as internal combustion engines and turbines, has been the de facto standard for many years within electric power generation but also rotating hydraulic and pneumatic machinery are highly developed technologies. A challenge for freepiston engine developers is to find linear equivalents of these machines with comparable performance.

The mechanical requirements for free-piston engine load devices are high since the load is coupled directly to the mover, and the load will be subjected to high acceleration forces. Secondary effects from the high accelerations such as cavitation in hydraulic cylinders must also be considered. Furthermore, the load device may be subjected to heat transfer from the engine cylinders.

Known free-piston engine loads include electric generators, hydraulic pumps and air compressors.
The dynamic properties of these differ widely. Important factors when determining the feasibility of a linear load for a free-piston engine are: Moving mass, physical size, efficiency and load force profile. The following characteristics are typical for the mentioned load devices:

- Hydraulic pumps typically work against a high discharge pressure. Combined with the incompressible working fluid, this allows a small unit with very low moving mass. The efficiency of such units is generally high and high operational flexibility has been demonstrated using electronically controlled hydraulic control systems with fast-acting valves in free-piston engines. The load force of a hydraulic pump is approximately constant, due to the constant discharge pressure.

- Electric generators can be relatively compact in size but often suffer from a high moving mass due to magnets or back iron in the mover, required to supply or direct the power generating magnetic flux within the machine. The efficiency of electric machinery is, however, generally very high. The load force of a permanent magnet electric machine coupled to a purely resistive load will be proportional to the translator speed, although other designs or the implementation of power electronics may allow variations on this.

- Air compressors were the original free-piston load devices but are not necessarily better suited for this purpose than the other two. The variable stroke of the free-piston engine may lead to poor volumetric efficiency of the air compressor when operating at varying load levels. If operating with atmospheric inlet pressure, a large compressor cylinder is needed resulting in a large and heavy construction. One advantage is that a stepped compressor piston can be applied, giving a compact multi-stage compressor. The load profile of an air compressor is like that of a gas filled bounce chamber in the compression phase and with an approximately constant load force when the discharge valves are open towards the end of the stroke.

Figure 7 illustrates the typical load characteristics of the mentioned free-piston engine loads. 


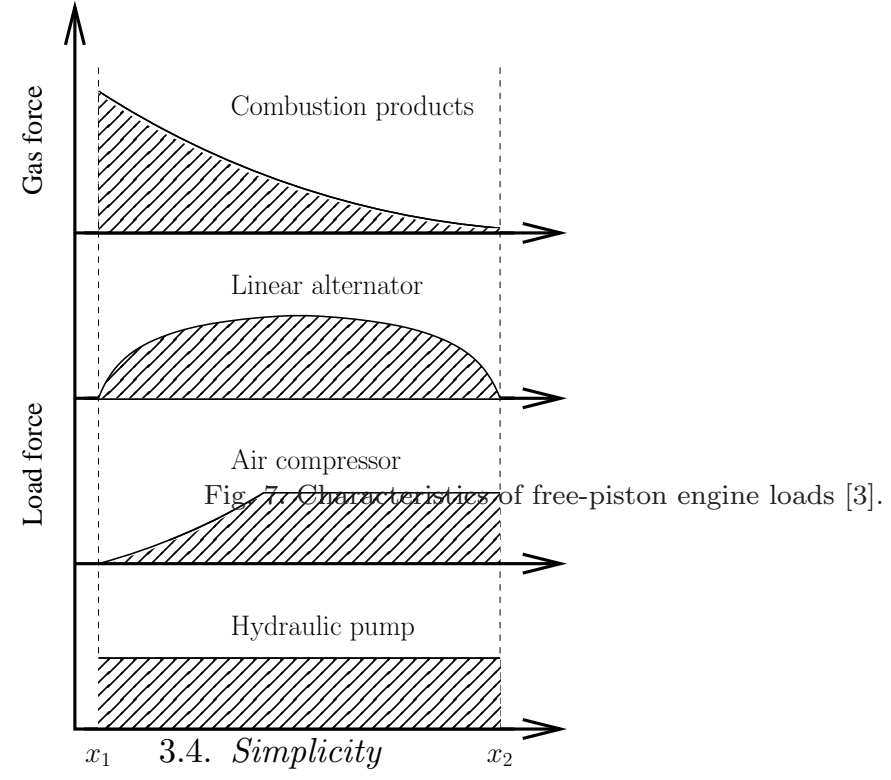

The simplicity of the free-piston engine compared to conventional technology is one of the driving forces behind many of the recent free-piston engine developments. The elimination of the crank mechanism reduces the number of parts and the complexity of a free-piston engine significantly and this potentially gives a number of advantages:

- Low frictional losses. Fewer moving parts in the free-piston engine give reduced frictional losses. In addition, the absence of a crankshaft eliminates losses due to crankshaft bearing friction, and the purely linear motion leads to very low side loads on the piston. This also reduces the cylinder lubrication requirements.

- Reduced manufacturing costs. The reduced number of parts in the free-piston engine results in lower manufacturing costs.

- Compactness. With reduced number of parts, the size and weight of the free-piston engine can be reduced, giving a more compact unit.

- Low maintenance costs and increased lifetime. The reduced number of parts and the reduced frictional losses reduce the maintenance costs of the free-piston engine.

\subsection{The combustion process}

Some reports have indicated that the combustion in free-piston engines benefits from the high piston speed around TDC. This leads to higher air velocity and turbulence level in the cylinder, which benefit air-fuel mixing and increase the reaction rate and flame speed. The high piston acceleration just after TDC leads to a rapid expansion, and timedependent chemical reactions, such as $\mathrm{NO}_{\mathrm{x}}$ formation, are potentially reduced.

Achten et al. [13] present experimental results showing significantly faster combustion in the Innas Free-Piston Engine compared to conventional engines. Values for ignition delay are found to be comparable to those found in conventional engines. Tikkanen et al. [9] present similar experimental results, and both groups indicate that combustion takes place predominantly in the premixed phase.

Fleming and Bayer [15] describe how theoretical thermodynamic analysis of the engine processes had to be drastically changed to achieve good agreement with experimental data, due to long ignition delays and high heat release rate in the free-piston engine. Baruah [16] reports significant advantages in emissions for a spark ignited free-piston engine over crankshaft engines, particularly for nitric oxides.

As a result of the particular operating characteristics, the in-cylinder heat transfer will also differ between the free-piston engine and conventional engines. The rapid power stroke expansion gives less time available for heat transfer from the hot gases to the cylinder wall, but increased in-cylinder gas motion may have the opposite effect and increase the heat transfer rate. However, Uludogan et al. [17] investigated the effects of increased engine speed on the combustion in a DI diesel engine and found that the advantages of increased fuel-air mixing far outweigh the disadvantages associated with increased heat transfer.

A particular feature of the free-piston engine is the ability of the combustion process to influence the speed of the expansion, due to the direct coupling of the combustion cylinder to the low-inertia moving member. A rapid combustion process and pressure rise may lead to a faster expansion and vice versa. In a conventional engine, the inertia of the crank system and flywheel ensures that the speed of the engine stays constant in the time frame of the combustion process. This intricate coupling between thermodynamics and mechanics makes detailed mod- 
elling of the free-piston engine complex, and models developed for conventional engines are therefore not necessarily suitable of modelling free-piston engine processes.

\subsubsection{Combustion optimisation}

The variable compression ratio in the free-piston engine may allow an optimisation of the combustion process not achievable in conventional engines. Given that a sufficiently accurate piston motion control system can be realised, the compression ratio can be regulated during operation to achieve best possible performance in terms of efficiency or emissions. Free-piston engines with compression ratios as high as 50:1 was reported in the mid-20th century [18].

\subsubsection{Homogeneous charge compression ignition}

Homogeneous charge compression ignition (HCCI) engines compress a premixed charge until it self-ignites, resulting in very rapid combustion but with poor control of ignition timing. The free-piston engine is well suited for this since the requirements for accurate ignition timing control are lower than in conventional engines. Potential advantages of HCCI include high efficiencies due to close to constant volume combustion and the possibility to burn lean mixtures to reduce gas temperatures and thereby some types of emissions. HCCI operation of free-piston engines has been attempted by among others Aichlmayr [3] and van Blarigan [19].

A quasi-HCCI approach is mentioned by Hibi and Ito [11]. Diesel fuel is injected very early in the compression process but after the intake and exhaust ports have closed. The fuel does not ignite at injection because the temperature and pressure are too low, but distributes more or less evenly within the cylinder and self-ignites when the pressure and temperature reach higher values. Ignition occurs at multiple points around the cylinder and the burning fuel spray with high local temperatures is avoided.

\subsubsection{Multi-fuel operation}

The nature of the free-piston engine makes it well suited for multi-fuel operation. The variable compression ratio combined with modern engine technology, such as variable fuel injection and valve timing, enable the free-piston engine to run satisfactorily on a wide range of fuels.

Flynn [20] reports the successful operation of a free-piston engine on a range of different fuels, in- cluding gasoline, diesel fuel and crude oil, and states that 'It seems that these engines do not care whether they get fuel with octane or cetane numbers'. He further states that the engine runs satisfactorily on vegetable and animal oils, with the only noticeable effect being the engine power output varying according to the heat content of the fuel. The same conclusion is also reached by other authors [21].

\subsection{Balancing}

The inherent vibration-free design was an often reported advantage of the early opposed piston air compressors and gas generators. These engines, from the earliest air compressor designs in the 1930's to the gas generators developed during 1940-1960, all had mechanical linkages synchronising piston motion. Aichlmayr [3] describes the first presentation of the Junkers free-piston air compressor at the Leipzig fair in 1936, where the excellent dynamic characteristics of the engines were demonstrated by suspending the compressors from the ceiling in a single steel cable and balancing pencils on the running engine's housing. Underwood [22] states that the smoothness of the General Motors GMR 4-4 'Hyprex' gas generator was 'frequently demonstrated by balancing a nickel on a horizontal machine surface'.

For the single piston and dual piston engine, however, balancing issues need to be addressed when mounting the engine. Vibrations may be cancelled out by running two or more engines in parallel, but this requires accurate control of engine speed. Another possibility is to apply counterweights, as demonstrated by Braun [23]. Disadvantages of counterweights are a more complex design, increased engine size and weight and additional friction losses. Achten [8] states that for the $17 \mathrm{~kW}$ hydraulic freepiston engine considered in his paper, vibrations can be accounted for when mounting the engine and that the acceleration forces will have about the same magnitude as in conventional engines.

\subsection{Mechanical requirements}

High pressure gradients, resulting from high fuel burn rate, lead to high forces and accelerations and increased mechanical requirements in the free-piston engine. Flynn [20] reported that the major problems in free-piston engines are the mechanical wear and damage, mainly due to high temperatures and pressures. 
Due to the variable stroke of the free-piston engine, high peak pressures may be also be experienced during transient operation or from operation of the engine at too high compression ratios.

\section{Reported free-piston engine applications}

Since the free-piston engine was first developed around 1930 a number of different designs have been proposed using the free-piston concept. The majority of these were, however, not commercially successful. This section gives an overview of known free-piston engine developments, with an emphasis on engines where experimental results or operational performance data have been reported. It should be noted that in addition to these a high number of patents describing free-piston machinery exist, where the actual development of the engines has not been reported.

\subsection{Free-piston air compressors}

The original free-piston configuration proposed by Pescara was an air compressor, and these machines proved to possess some very attractive features. Despite the large research efforts on the freepiston gas generator during 1940-1960, the air compressor is by many considered to be the only really successful free-piston engine concept. The excellent performance of the air compressors was a strong contributor to the later significant research efforts put into the free-piston gas generator.

These engines were of the opposed piston type, making them vibration-free. Farmer [4] discusses how the interaction between the bounce chamber and the compressor cylinders controls the compression energy delivered to the combustion cylinder and makes the engine essentially self-regulating.

Despite its apparent good performance, the freepiston air compressor did not gain widespread commercial success. No reports of serious lacks or flaws in the concept explaining this can be found, except that the free-piston air compressor had a narrow output range. Most reports are, in fact, of the opposite opinion, such as McMullen and Payne [24] who state that the free-piston air compressor has proved 'reliable and efficient under all conditions of service'.

Beachley and Fronczak [25] evaluate the lack of success of the free-piston air compressor and present some possible factors, including that (a) stationary installations tended to use cheaper electric motors to drive compressors; (b) demand for variable power output disfavoured the narrow-output free-piston air compressor for portable applications; (c) low fuel prices and a limited market for such applications discouraged the development of such unconventional design.

\subsubsection{Reported free-piston air compressors}

Junkers One of the earliest successful free-piston engine applications was the air compressor developed by German company Junkers in the early 1930's. The Junkers air compressor was first exhibited in 1936 and was used by the German navy during World War 2 to provide compressed air for launching torpedoes. After the war, US company Worthington continued development on the Junker model with only minor design changes [27].

The Worthington-Junkers air compressor was an opposed piston, diesel-powered unit with multiple compressor stages and no rebound device, as the compressed air left in the clearance volumes in the compressor cylinders provided the work to drive the next compression. This was possible because the compressor had constant power output and the fuel pump was set to deliver a fixed amount of fuel, with on-off control regulating the delivery of compressed air [4].

A mechanical synchronisation mechanism connecting the two pistons ensured vibration-free operation. Starting was done with compressed air, by manually moving the pistons to its outer positions, pressurising the compressor cylinders and then releasing the pistons. London and Oppenheim [26] report that a compression ratio of 40:1 was achieved with this method, virtually ensuring ignition and unproblematic starting.

Toutant [27] reports that the unit occupied about $50 \%$ of the space required by a conventional electrically driven compressor and that this, together with good fuel efficiency, gave the unit great advantages in submarine installations.

Braun linear engine In a more recent approach, Braun and Schweitzer [23] present a single piston free-piston engine. The load device in the described engine is an air compressor but the authors state that any suitable linear load may be applied. The engine operates on a crankcase-scavenged, two-stroke spark ignited cycle and counterweights make the engine completely balanced. A compression ignition 
version of the engine is also reported to have been successfully operated.

Extensive testing of the engine is reported, among this 15,000 hours of operation without breakdown and 40,000 consecutive starts without a miss. The authors state that superior fuel economy is possible due to the on/off control of the compressor, where conventional engine-compressor sets would run idle.

\subsection{Free-piston gas generators}

In the late 1940's the free-piston gas generator attracted interest for use in large-scale powerplants, and later also for vehicle propulsion. Many variants emerged, and both General Motors and Ford Motor Company had working prototypes aimed for vehicle propulsion. Larger free-piston gas generators were installed in a number of stationary powerplants and in some marine installations. Much experience in the operation of free-piston machinery is reported in this period.

These engines were typically diesel powered, opposed piston engines with mechanical synchronisation of the two pistons. The synchronisation mechanism did, in addition to evening out possible force differences, also drive the accessories such as fuel injection pump, oil pump and water pump. The starting of the engines was, similar to the Junkers air compressor, performed by rapidly introducing compressed air into the bounce chambers.

These engines were highly supercharged and operated on higher mean effective pressures than conventional diesel engines [26]. The most important advantages of free-piston gas generators were: low fuel quality requirements, vibration-free design, good dynamic response and low turbine material requirements due to lower inlet temperatures. London and Oppenheim [26] state that the fuel economy of the free-piston gas generator power plant was competitive with conventional diesel engines and 80$100 \%$ better than conventional gas turbine plants. The specific weight was somewhere between the low specific weight of the gas turbine and the high specific weight of the conventional diesel engine.

McMullen and Ramsey [28] claim that the higher free-piston gas generator efficiency compared to the conventional gas turbine was due to the higher compression pressures. They state that free-piston engines could achieve an end-of-compression pressure of 100 times the atmospheric pressure, whereas in the simple type gas turbine this value was around
6. In relation to this, Aichlmayr [3], however, notes that the gas turbine was in its infancy in the 1940's and that this must be considered when comparing the two plants.

A particular feature of the free-piston gas generators, giving them an advantage over conventional gas turbines, was the low temperature of the gas supplied to the power turbine. This was a result of the work required to compress the inlet air already having been extracted before the gas was fed to the turbine. This allowed the free-piston unit to be placed further away from the power turbine without extensive heat losses from the hot gases, a feature that was one of the driving forces behind the development of such engines for automotive use.

Despite some well documented advantages, the free-piston gas generator never became a real competitor to either the diesel engine or the gas turbine. Some of the reasons for the limited success of the free-piston gas generator are:

- High development efforts were put in to both conventional diesel engines and gas turbine technology, giving rapid performance increases.

- The matching of a pulsating-flow compressor with a continuous-flow turbine proved problematic, giving low part-load efficiency and limiting the gas generator to constant power applications $[18,20]$.

- High failure rates and low lifetime and availability were reported, related to high pressure and temperature operation [20].

- The engines did not provide large advantages in weight or fuel economy compared to conventional engines and could not compete with the power to weight ratio of the gas turbine.

With the maturing of conventional gas turbine technology, development of the free-piston gas generator was largely abandoned in the early 1960's. [3, 18, 20]

\subsubsection{Reported free-piston gas generator applications}

SIGMA The model GS-34 free-piston gas generator manufactured by Société Industrielle Générale de Mécanique Appliquée (SIGMA) in France was one of the most successful free-piston engines ever made. The development of the GS-34 was finished in 1944, and it was based on Pescaras patents.

The GS-34 was an opposed piston, diesel powered unit aimed for large scale applications such as marine and industrial powerplants. The engine had an 
output power of around $1000 \mathrm{~kW}$ and a setup with multiple engines in parallel, supplying a single turbine was frequently used. Huber [29] reports that in October 1957, 90 gas generators with a total running time of about 250000 hours were in commercial use and more units were on order.

The engines were used in various installations such as stationary plants, the largest one being the Cherbourg power plant consisting of 8 gas generators feeding one turbine and giving $6000 \mathrm{~kW}$ electric power output. As marine powerplants, free-piston gas generators were installed in 21 minesweepers of the French Navy. Huber reports favourable results with excellent vessel manoeuvrability using gas generators compared to conventional diesel engine propulsion. Other marine installations are also mentioned, in addition to other applications such as locomotives and the powering of pumps and compressors.

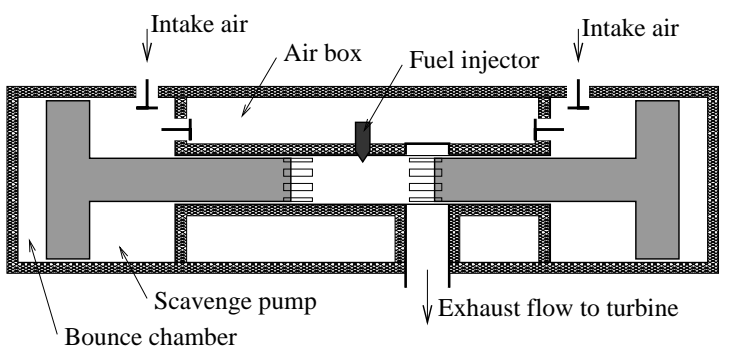

Fig. 8. Illustration of the SIGMA GS-34 free-piston gas generator [26]. (Note that the illustration is simplified for clarity.)

\begin{tabular}{|c|c|}
\hline Power output & $1138 \mathrm{hp}$ \\
\hline Weight (approx.) & $8000 \mathrm{~kg}$ \\
\hline Speed & $613 \mathrm{rpm}$ \\
\hline Cylinder bore & $0.34 \mathrm{~m}$ \\
\hline Bounce chamber bore & $0.90 \mathrm{~m}$ \\
\hline Stroke & $0.44 \mathrm{~m}$ \\
\hline Compressor pressure ratio & 5.42 \\
\hline Engine compression ratio & 8.5 \\
\hline Piston mass & $503 \mathrm{~kg}$ \\
\hline Overall thermal efficiency & $34.6 \%$ \\
\hline
\end{tabular}

General Motors General Motors (GM) gained interest in the free-piston engine concept after testing a number of free-piston engines including the
SIGMA GS-34 gas generator in the mid-1950's. This ultimately led to the development of two free-piston gas generators, the GM-14, which was based on the SIGMA engine, and the GMR 4-4 'Hyprex'.

A marine powerplant based on six GM-14 units was installed in the GTS William Patterson, a United States Maritime Administration vessel, in the late 1950's but with disappointing results. Specht [30] evaluates the powerplant and reports a number of problems during the test period but also explains how some of them were addressed. Problems include air pulsation and noise in the machinery room, piston ring breakage, difficulties in matching gas generators with turbines, and high maintenance costs. Reported advantages of the powerplant included high manoeuvrability, the possibility of rapid change in power level, easy maintenance of the units with low implications on vessel operation, and high flexibility in operation due to the 6 gas generators and 2 turbines. The fuel economy is reported to have been comparable to conventional technology. Specht concludes that the gas generator plant is unsuitable for scaling up due to the necessary increase in number of units, increasing labour costs for maintenance and operation.

The GMR 4-4 'Hyprex' was a dual ('siamesed') opposed piston, diesel free-piston engine aimed for automotive applications, and had power output of around $185 \mathrm{~kW}$ at $2400 \mathrm{rpm}$. Underwood [22] lists the reasons for the chosen siamesed design, which include a more compact unit and reduced pressure oscillations at the turbine inlet. The engine was installed in a car, the XP-500, for testing, making this the first car in the world to be powered by a freepiston engine. Despite optimistic reports from the GM engineers, the Hyprex could not compete with conventional engines and was abandoned [18].

Ford Like General Motors, Ford saw a potential in the free-piston gas generator for automotive applications in the mid 1950's. Frey et al. [31] mention the potential advantages of mounting the gas generator in the front of the vehicle and the power turbine in the rear, thereby eliminating the drive tunnel and achieving better weight distribution (this is also discussed by Underwood of General Motors [22]).

Frey et al. showed analytical models for the design of a free-piston gas generator and they described the development of a $150 \mathrm{hp}, 2400 \mathrm{rpm}$ unit. They report initial development difficulties regarding starting, breakage of piston rings, injection pump fail- 
ures and poor combustion, but describe how most of these were addressed by improvements in the design.

Noren and Erwin [21] described the development of the Ford model 519 free-piston powerplant and the implementation of that in a farm tractor. The authors state that in the tractor, the free-piston powerplant is more compact, has lower weight and provides more freedom in the mounting of the engine than a comparable conventional diesel engine. Based on results from the test vehicle they report superior torque characteristics for the free-piston gas generator unit over a conventional piston engine, illustrated in Figure 9. Where the crankshaft engine torque will decrease at reducing speeds and the engine will finally stall or a gear shift has to be made, the free-piston unit torque increases at lower speeds. Other reported advantages of the free-piston unit are vibration free operation and low noise.
Fig. 9. Torque characteristics of the free-piston powerplant compared to a conventional engine [21].

Kvarner In a more recent approach, the Norwegian company Kværner ASA designed an 8-cylinder, $8 \mathrm{MW}$ free-piston gas generator together with Norwegian University of Science and Technology (NTNU) [12]. The engine is a single-piston gas generator, illustrated in Figure 10, and experimental results from a one-cylinder test engine is reported.

The developers derived a control strategy for piston motion control, controlling TDC, BDC and synchronisation of the cylinders in addition to supervisory control objectives of load and combustion optimisation [32]. This engine is the only reported modern attempt of building a free-piston gas generator. However, through personal communication with the developers the authors have learnt that this project Turbine engine was abandoned before completion. The reasons for this are not known.

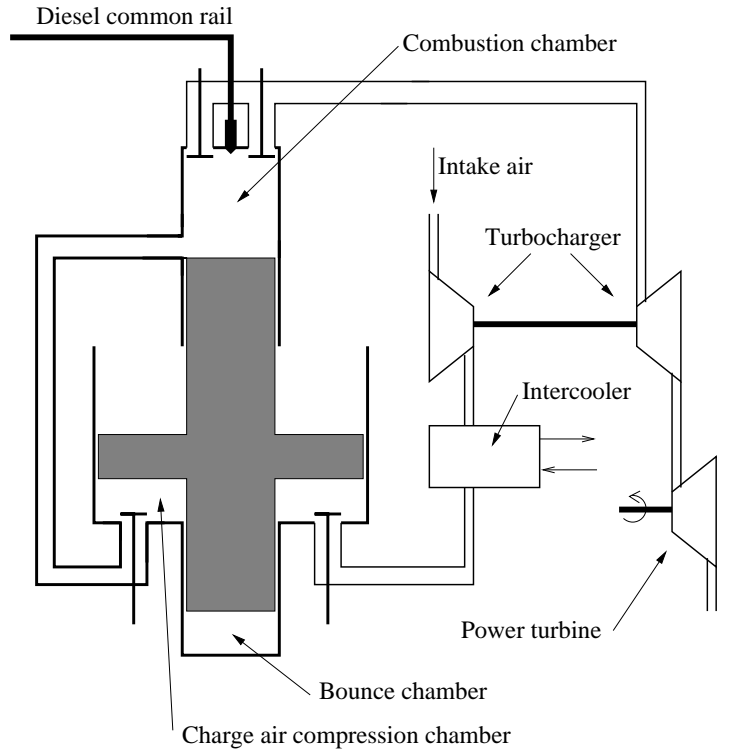

Fig. 10. Kværner KLC free-piston gas generator [12].

\subsection{Hydraulic free-piston engines}

Many of the modern approaches in free-piston engine technology are hydraulic engines, in which the combustion piston is directly coupled to a hydraulic pump cylinder. A number of projects are ongoing, both within academia and in industry. Most of these units are aimed at off-highway vehicles such as forklift trucks and earth-moving machinery and, consequently, most developments are of small size (typically $30-50 \mathrm{~kW}$ ). Such vehicles typically have high hydraulic loads from vehicle accessories and propulsion, and they are commonly powered by a conventional diesel engine coupled to a hydraulic pump.

Hydraulic free-piston engines may apply a hydraulically driven rebound device, using part of the produced hydraulic energy to return the piston, or a bounce chamber. A number of prototypes have been developed in recent years and experimental results from these are currently being reported. The reports show generally good fuel economy and very good performance at part load.

\subsubsection{Reported hydraulic free-piston engine applications}

Toyohashi University Researchers at Toyohashi University of Technology in Japan have been doing 
research in the field of hydraulic free-piston engines for more than 20 years. They have reported experimental results from both single piston [33] and opposed piston [11] diesel powered free-piston engines.

The latter is the latest published work, with reported engine hydraulic thermal efficiency of $31 \%^{2}$. The authors state that this value stays practically constant even with very low hydraulic power output. The fuel injection is hydraulically actuated and the fuel is injected very early in the compression process to achieve a combustion process similar to that of a homogenous charge compression ignition engine.

Hibi and Ito [11] further present an alternative piston synchronisation method for the opposed piston engine, eliminating the traditional mechanical linkage. The pistons in the hydraulic free-piston engine are synchronised by using a combination of the electronically controlled hydraulic rebound device and a mechanical spring. A small synchronisation error is reported, but this is not large enough to affect the performance of the engine.

Innas The Dutch company Innas BV is among the research leaders within free-piston technology today. They have developed a single piston, diesel powered, hydraulic free-piston engine, intended as an alternative to conventional engine and hydraulic pump systems in off-highway vehicles [13]. The implementation of the engine in a fork lift truck is also described [34]. The developers claim that reduced exhaust emissions and lower fuel consumption can be achieved with the engine, due to a mechanically less complex design and high operational flexibility.

The Innas Free-Piston Engine engine has $17 \mathrm{~kW}$ power output, and indicated efficiencies of around $50 \%$ are reported [14]. The construction of the engine is shown in Figure 11, and it utilises a complex hydraulic control system. The engine uses the pulse pause modulation control principle, described earlier in this text. Fuel consumption is reported to be around $20 \%$ lower than a conventional engine-pump unit and at low loads even $50 \%$ lower [13].

Innas is currently also involved in a free-piston engine generator project, under a European Union programme.

Technische Universität Dresden Researchers at the German university Technische Universität Dres-

\footnotetext{
2 For comparison: a conventional diesel engine with fuel efficiency of $35 \%$ coupled to a hydraulic pump with efficiency $85 \%$ would give a total ('hydraulic') efficiency of $30 \%$.
}

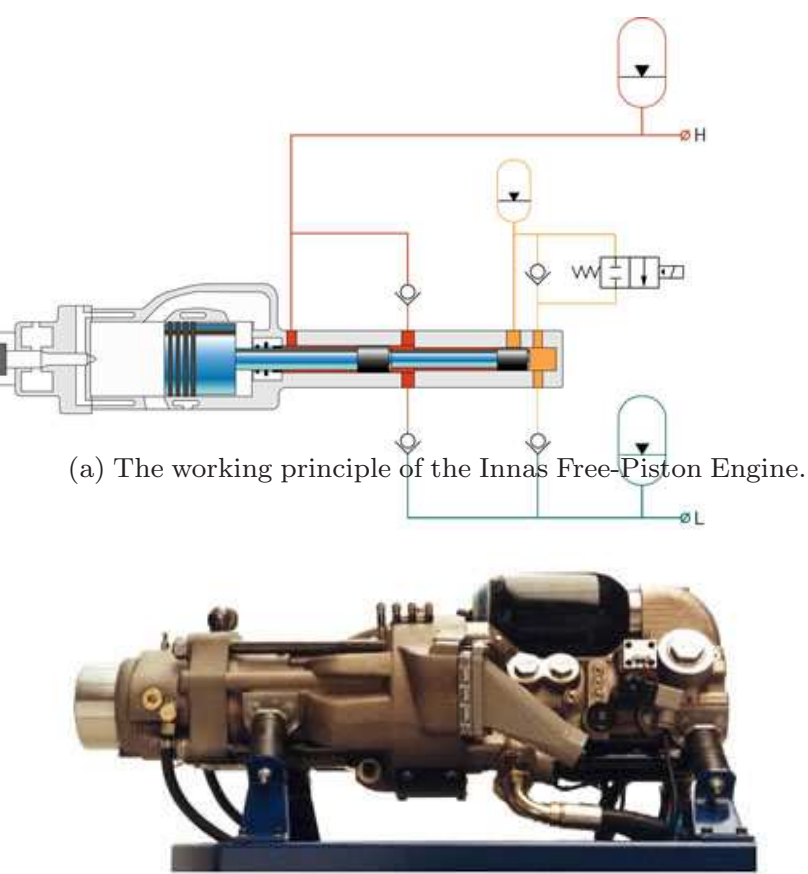

(b) Photograph of the engine.

Fig. 11. The Innas Free-Piston Engine (reprinted with the permission of Innas BV).

den report the development of a hydraulic freepiston engine with a patented hydraulic control system $[6,35]$. The unit is a single piston engine similar to the Innas Free-Piston Engine, and the engine illustrated in Figure 1. Unlike the Innas engine, it is controlled with on/off control. The developers present the implementation of the engine in a hydraulic circuit and report a hydraulic efficiency of above $30 \%$.

Tampere University Researchers at Tampere University of Technology, Finland, describe the design and performance of a dual piston hydraulic freepiston engine prototype, illustrated in Figure 2 [9]. The engine is diesel powered, utilising electronic control with a common rail injection system. Starting is done with stored hydraulic energy, using the hydraulic pump to drive the piston.

Test results from the first test engine are described, and show a piston motion different from that of conventional engines and piston acceleration peak values of more than double than those of comparable crankshaft engines. In comparison to conventional engine piston motion, it is observed that maximum piston velocity is lower for the free-piston 
engine with equal mean piston speeds. The developers state that the relative long periods of the stroke with almost constant piston velocity and the short turn times at the dead centres benefit the hydraulic pump circuit. Total efficiency of $20 \%$ was reported.

The developers report cycle-to-cycle variation in stroke for each cylinder of $\pm 1 \%$, giving a variation in compression pressure of around $\pm 15 \%$. Combustion pressures varying between 77-88 bar are reported. The authors state that the results from the initial tests were satisfactory as proof-of-concept for the hydraulic dual piston engine but that the control issues should be adressed. Recent publications investigating engine control issues include Tikkanen and Vilenius [36].

\subsection{Free-piston engine generators}

The free-piston engine generator consists of a freepiston engine coupled to a linear electric machine. Such technology is currently being explored by a number of research groups worldwide. The high efficiencies of electrical machinery, along with flexibility and controllability, make this an interesting concept. A driving force behind the interest in free-piston engine generators is the automotive industry's increasing interest in hybrid-electric vehicle technology.

Free-piston engine generator designs of both single piston and dual piston types have been reported. A bounce chamber may be applied in the single piston engine, but the use of the electric machine as rebound device has also been proposed. Implementation of appropriate power electronics may allow the use of the electric machine in motoring mode to aid engine control and for starting.

\subsubsection{Reported free-piston engine generator applications}

West Virginia University Researchers at University of West Virginia describe the development of a spark ignited dual piston engine-generator [37]. They have thoroughly documented their work and findings in a number of publications, both concerning linear alternator design, design and operation of the combustion engine and analysis of the combined system [10,37-40]. An engine prototype is reported to have achieved $316 \mathrm{~W}$ power output at $23.1 \mathrm{~Hz}$, with $36.5 \mathrm{~mm}$ bore and $50 \mathrm{~mm}$ maximum stroke. High cycle-to-cycle variations are reported, particularly at low loads.
This group of researchers is the most successful within academia regarding free-piston engine generator research. It is one of very few that have reported the successful development of a running prototype.

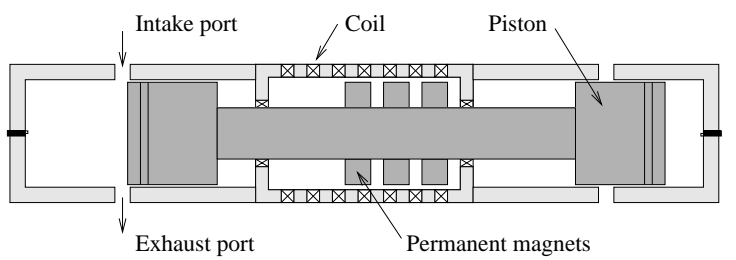

Fig. 12. Illustration of the free-piston engine generator prototype developed at University of West Virginia [38].

Sandia National Laboratories Van Blarigan [19] presents the design of a dual piston free-piston engine generator with $40 \mathrm{~kW}$ electric power output. The engine employs homogeneous charge compression ignition (HCCI) and is aimed to operate on a variety of hydrogen-containing fuels. The HCCI combustion is to achieve faster combustion than that in SI or CI engines, and to burn lean mixtures at high compression ratios and thereby reduce $\mathrm{NO}_{\mathrm{x}}$ emissions formation. Test results from a compression-expansion machine are presented, showing close to constant volume combustion with hydrogen, bio-gas and ammonia at equivalence ratios of around 0.3 .

Van Blarigan states that operation on lean mixtures and with low mean effective pressures is possible without efficiency penalties due to the low frictional losses in the free-piston engine.

KTH, Stockholm A research group from Royal Institute of Technology (KTH), Stockholm, Sweden, has published a number of articles evaluating different electrical machine possibilities for a free-piston engine generator $[41,42]$. They state that finding an electrical machine fulfilling their requirements is a challenging task but find that the permanent magnet, transverse-flux machine is the most promising candidate. The transverse-flux machine benefits from a low translator mass compared to other permanent magnet configurations but suffers from a low power factor and high manufacturing costs. The authors state that all the evaluated machines have satisfactory efficiency but that none of them come close to achieving the specific power requirements.

Based on their initial findings, the transverse-flux machine is further investigated and the development 
of a prototype is reported [43]. Based on the prototype testing and further design optimisation, it is concluded that the transverse-flux machine may satisfy the requirements for an electric machine in a free-piston engine generator.

\section{Conclusions}

The basic design and unique features of the freepiston engine have been discussed. Although several reports have confirmed that the free-piston engine is a viable concept, more research is required to investigate potential advantages over conventional technology. The area with most uncertainty is clearly that of piston motion control. Most of the potential advantages of the free-piston engine depend on an appropriate control system being realisable. Optimisation of the combustion process and multi-fuel or HCCI operation require compression ratio control, and elimination of vibrations by running several units in opposite phases requires accurate control of engine speed.

A review of reported free-piston engine applications presented performance data and operational experience of the most successful free-piston engine developments to date. Both engines developed in the period 1930-1960, namely free-piston air compressors and gas generators, and more recent approaches of hydraulic and electric free-piston engines were reviewed. The most promising technology at the moment appears to be the hydraulic freepiston engines, with several developments showing favourable performance compared to conventional technology by fully utilising the powers of modern, microprocessor-based, control technology.

Free-piston engine generators are also under investigation by a number of research groups worldwide. The flexibility and controllability of electric machinery, along with increasing interest in technologies such as hybrid-electric vehicles and the allelectric ship concept, are incentives driving the development of free-piston engine generator technology, and the performance of such engines is expected to improve significantly in the future.

\section{References}

[1] Hekkert MP, Hendriks FHJF, Faaij APC, Neelis ML. Natural gas as an alternative to crude oil in automotive fuel chains well-to-wheel analysis and transition strategy development, Energy Policy, 2005:33:579-594.
[2] Pescara RP. Motor compressor apparatus, US Patent 1,657,641, 1928.

[3] Aichlmayr HT. Design Considerations, Modeling, and Analysis of Micro-Homogeneous Charge Compression Ignition Combustion Free-Piston Engines, PhD Thesis, University of Minnesota, 2002.

[4] Farmer HO. Free-piston compressor-engines, Proc. Inst. Mech. Eng., 1947:156:253-271.

[5] Pescara RP. Motor compressor of the free piston type, US Patent 2,241,957, 1941.

[6] Brunner H, Winger A, Feuser A, Dantlgraber J, Schäffer R. Thermohydraulische Freikolbenmaschine als Primäraggregat für mobilhydraulische Antriebe, 4th Intl Fluid Power Conference, Dresden, 2004.

[7] Tikkanen S, Herranen M, Savela R, Vilenius M. Simulation of a hydraulic free piston engine: A dual piston case, Proc. Sixth Scandinavian international conference on fluid power, pp. 339-349, 1999.

[8] Achten PAJ. A review of free piston engine concepts, SAE Paper 941776, 1994.

[9] Tikkanen S, Lammila M, Herranen M, Vilenius, M. First cycles of the dual hydraulic free piston engine, SAE Paper 2000-01-2546, 2000.

[10] Clark N, Nandkumar S, Atkinson C, Atkinson R, McDaniel T, Petreanu S et al. Operation of a smallbore two-stroke linear engine, Proc. of the Fall Technical Conference of the ASME Internal Combustion Engine Division, 1998:31-1:33-40.

[11] Hibi A, Ito T. Fundamental test results of a hydraulic free piston internal combustion engine, Proc. Inst. Mech. Eng., 2004:218:1149-1157.

[12] Johansen TA, Egeland O, Johannesen EA, Kvamsdal R. Dynamics and control of a free-piston diesel engine, ASME J. Dynamic Systems, Measurement and Control, 2003:125:468-474.

[13] Achten PAJ, van den Oever JPJ, Potma J, Vael GEM. Horsepower with brains: The design of the Chiron free piston engine, SAE Paper 2000-01-2545, 2000.

[14] Somhorst JHE, Achten PAJ. The combustion process in a DI Diesel hydraulic free piston engine, SAE Paper 960032, 1996.

[15] Fleming JD, Bayer RJ. Diesel combustion phenomena as studied in free piston gasifiers, SAE Paper 630449, 1963.

[16] Baruah PC. A free-piston engine hydraulic pump for an automotive propulsion system, SAE Paper 880658, 1988.

[17] Uludogan A, Foster DE, Reitz RD. Modeling the effect of engine speed on the combustion process and emissions in a DI Diesel engine, SAE Paper 962056, 1996.

[18] Amann CA. Evaluating alternative internal combustion engines: 1950-1975, Trans. of the ASME - Journal of Engineering for gas turbines and power, 1999:121:540-5.

[19] van Blarigan P. Advanced Internal Combustion Electrical Generator, Proc 2002 U.S. DOE Hydrogen Program Review, NREL/CP-610-32405, 2002.

[20] Flynn G Jr. Observations on 25,000 hours of free-pistonengine operation, SAE Transactions 1957:65:508-515.

[21] Noren OB, Erwin RL. The future of the freepiston engine in commercial vehicles, SAE Transactions 1958:66:305-314.

[22] Underwood AF. The GMR 4-4 "HYPREX" engine A concept of the free-piston engine for automotive use, SAE Transactions 1957:65:377-391. 
[23] Braun AT, Schweitzer PH. The Braun linear engine, SAE paper 730185, 1973.

[24] McMullen JJ, Payne WG. Performance of free-piston gas generators, Transactions of the ASME 1954:76:1-13.

[25] Beachley NH, Fronczak FJ. Design of a free-piston engine-pump, SAE Technical Paper 921740, 1992.

[26] London AL, Oppenheim AK. The free-piston engine development - Present status and design aspects, Transactions of the ASME, 1952:74(2):1349-1361.

[27] Toutant WT. The Worthington-Junkers free-piston air compressor, Journal of the American Society of Naval Engineers, 1952:64(3):583-594.

[28] McMullen JJ, Ramsey R. The free-piston type of gas turbine plant and applications, Transactions of the ASME, 1954:76:15-29.

[29] Huber R. Present state and future outlook of the free-piston engine, Transactions of the ASME, 1958:80(8):1779-1790.

[30] Specht DH. Evaluation of free piston-gas turbine marine propulsion machinery in GTS William Patterson, SAE Paper 620280, 1962.

[31] Frey DN, Klotsch P, Egli A. The automotive free-pistonturbine engine, SAE Transactions, 1957:65:628-634.

[32] Johansen TA, Egeland O, Johannesen EA, Kvamsdal R. Free-piston diesel engine timing and control - towards electronic cam- and crankshaft, IEEE Trans. Control Systems Technology, 2002:10:177-190

[33] Hibi A, Kumagai S. Hydraulic free piston internal combustion engine - test result, Hydraulic Pneumatic Mechanical Power, 1984:30(357):244-9.

[34] Vael GEM, Achten PAJ. The Innas Fork Lift Truck, Working Under Constant Pressure, Proc. 1. IFK, IFAS/RWTH Aachen, 1998.

[35] Brunner H, Dantlgraber J, Feuser A, Fichtl H, Schäffer R, Winger A. Renaissance einer Kolbenmachine, Antriebstechnik, 2005:4:66-70.

[36] Tikkanen S, Vilenius M. Control of a dual hydraulic free piston engine, Int. J. Vehicle Autonomous Systems, 2006:4(1):3-23.

[37] Clark N, Nandkumar S, Atkinson C, Atkinson R, McDaniel T, Petreanu, $\mathrm{S}$ et al. Modelling and development of a linear engine, ASME Spring Conference, Internal Combustion Engine Division, 1998:30(2):49-57.

[38] Famouri P, Cawthorne WR, Clark N, Nandkumar S, Atkinson C, Atkinson R et al. Design and testing of a novel linear alternator and engine system for remote electrical power generation, Proc. IEEE Power Engineering Society winter meeting, pp. 108-112, 1999.

[39] Clark N, Nandkumar S, Atkinson C, Atkinson R, McDaniel T, Petreanu S et al. Numerical simulation of a two-stroke linear engine-alternator combination, SAE Paper 1999-01-0921, 1999.

[40] Clark N, Nandkumar S, Atkinson C, Atkinson R, McDaniel T, Petreanu S et al. Fundamental analysis of a linear two-cylinder internal combustion engine, SAE Paper 982692, 1998.

[41] Arshad WM, Bäckström T, Thelin P, Sadarangani C. Finding an appropriate electrical machine for a free piston generator, Proc. Intl Battery, Hybrid and Fuelcell Electric Vehicle Symposium and Exhibition, Busan, Korea, 2002.
[42] Arshad WM, Thelin P, Bäckström T, Sadarangani C. Alternative electrical machine solutions for a free piston generator, The Sixth Intl Power Engineering Conference (IPEC2003), Singapore, 2003.

[43] Arshad WM, Thelin P, Bäckström T, Sadarangani C. Use of transverse-flux machines in a free-piston generator, Proc. IEEE Intl Electric Machines and Drives Conference (IEMDC), Madison, Wisconsin, USA, 2003. 